\title{
Pancoast Syndrome Revealing a Vertebral Giant Cell Tumor
}

EL Ghazi $\mathrm{M}^{1^{*}}$, Ahmanna H-C1, Rais $\mathrm{H}^{2}$, Mssouguar $\mathrm{Y}^{3}$, Boutakioute $\mathrm{B}^{1}$, Idrissi Ouali $\mathrm{M}^{1}$, Cherif Idrissi Ganouni $\mathrm{N}^{1}$

${ }^{1}$ Department of Radiology, ${ }^{2}$ Department of Pathology, ${ }^{3}$ Department of Thoracic Surgery, Arrazi Hospital, Mohamed VI University Hospital, Cadi Ayyad University, Marrakech, Morocco

DOI: $10.36347 /$ simcr.2020.v08i01.015

| Received: 27.12.2019 | Accepted: 04.01.2020 | Published: 18.01.2020

*Corresponding author: Mohamed EL GHAZI

Abstract

Case Report

Introduction: Giant cell tumor is a locally aggressive benign primitive bone tumor, the vertebral location is exceptional, and rarely associates with an aneurysmal cyst, we report a case of vertebral giant cell tumor, colonized by an aneurysmal cyst revealed by a Pancoast syndrome. Case presentation: We report the case of a 19 years old female patient, present since 6 months a symptom of horner syndrome, with pain located on the shoulder and the inter scapula-vertebral space, inflammation blood test were negative, radiological assessment showed a lytic lesion process centered on D1 extends into spine canal and inside the thorax, Biopsy: Giant cell tumor, colonized by an aneurysmal cyst. Conclusion: The giant cell tumor with vertebral location is a very aggressive tumor; IT can be associated with an aneurysmal cyst responsible for tumor hypervascularization, necessitating preoperative embolization.

Keywords: Pancoast syndrome, Giant cell tumor, aneurysmal cyst.

Copyright @ 2020: This is an open-access article distributed under the terms of the Creative Commons Attribution license which permits unrestricted use, distribution, and reproduction in any medium for non-commercial use (NonCommercial, or CC-BY-NC) provided the original author and source are credited.

\section{INTRODUCTION}

Giant cell tumor is a locally aggressive benign primitive bone tumor. The vertebral location is exceptional, and rarely associates with an aneurysmal cyst. We report a case of vertebral giant cell tumor, colonized by an aneurysmal cyst revealed by a Pancoast syndrome, which is the originality of this observation.

\section{Case Presentation}

We report the case of a 19 years old female patient, with no significant past medical history. She present since 6 months with a pain located on the shoulder and the inter scapulo-vertebral space, which extends to the inner side of the arm and the forearm until the last two fingers of the left hand; Miosis, narrowing of the palpebral fissure, and an exophthalmia of the left eye. Inflammation blood test, were negative, Radiological assessment including: Chest X-ray, thoracic CT and cervical MRI were performed. Chest X ray showed a homogeneous dense left apical opacity with a clean outer edge and an internal edge embedded in the mediastinum (Fig-1).

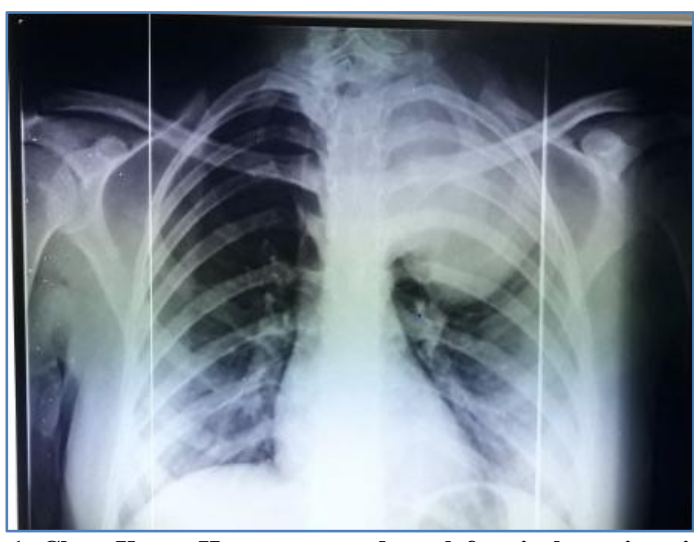

Fig-1: Chest X ray: Homogeneous dense left apical opacity with a clean outer edge and an internal edge embedded in the mediastinum

Thoracic CT showed a lytic lesion process centred on D1 extending into the spine canal and inside the thorax with lysis of the vertebral body and posterior arch of D1 (Fig 2). 


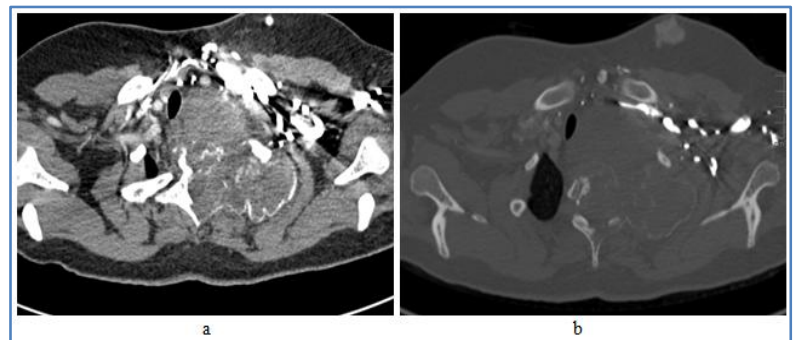

Fig-2: Thoracic CT scan: Axial C+ arteriel phase A-mediastinal window B- bone window Lytic lesion process centred on D1 that extends into the spine canal and inside of the thorax with lysis of the vertebral body and posterior arch of D1

This process comes into contact with the costo-vertebral angles of C7 to D4, encapsulates the left pulmonary artery and compresses the aero-digestive tract (Fig.3).
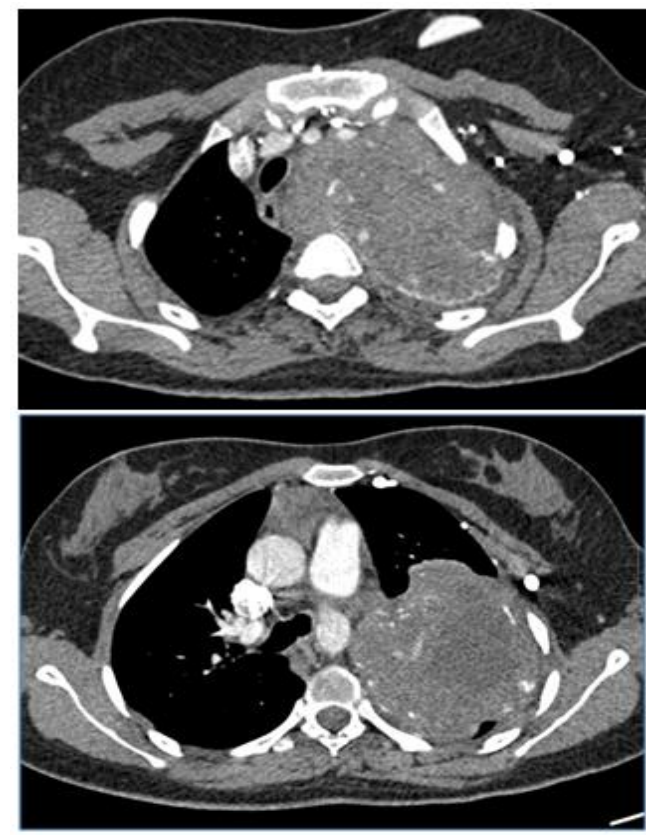

Fig-3: This process comes into contact with the costo-vertebral angles of $\mathrm{C} 7$ to $\mathrm{D} 4$ encapsulate the left pulmonary artery and compresses the aero-digestive tract

Lysis of the vertebral body and the posterior arch of D1 with antelisthesis of D1 / D2.(Fig 4)

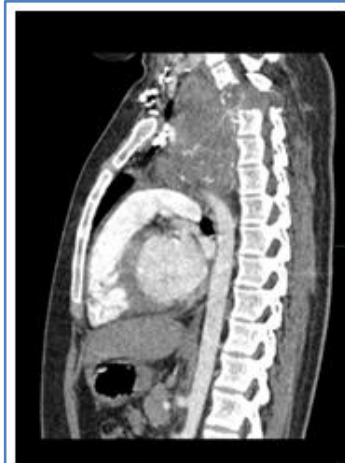

a

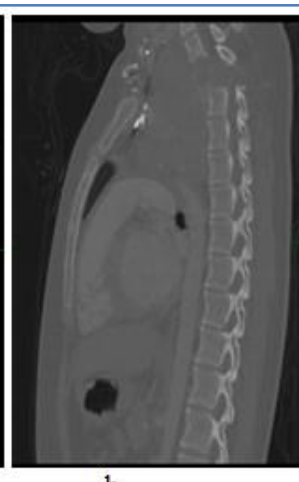

b
Fig-4: A sagittal reconstruction CT scan, mediastinal window. BSagittal reconstruction CT scan, bone window
Lysis of the vertebral body and the posterior arch of D1 with antelisthesis of D1 / D2

Encapsulation of supraaortic trunks above by the mass associated with a compression of the aerodigestive tract (Fig 5).

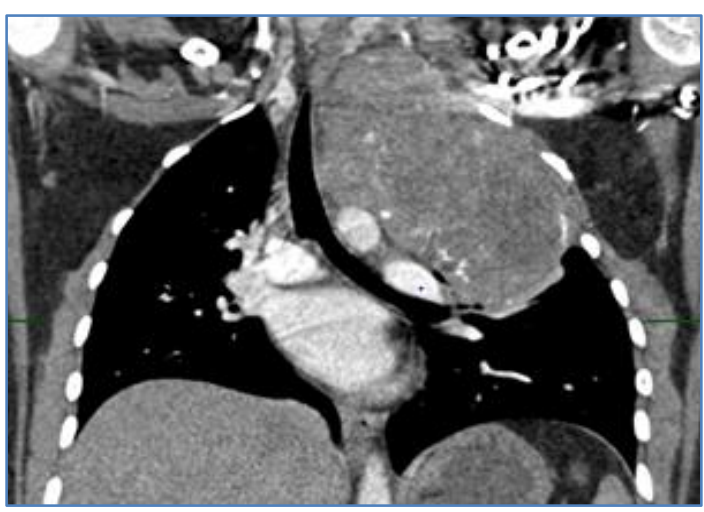

Fig-5: Coronal reconstruction CT scan, mediastinal window Encapsulation of supraaortic trunks above by the mass associated with a compression of the aero digestive tract

The cervical MRI showed a multilocular lytic lesion process responsible of the lysis of the body and the posterior arch of D1 on hyposignal T1 and heterogeneous hypersignal on T2 (Fig.6).

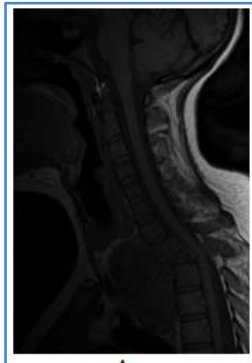

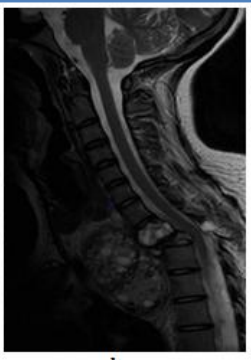

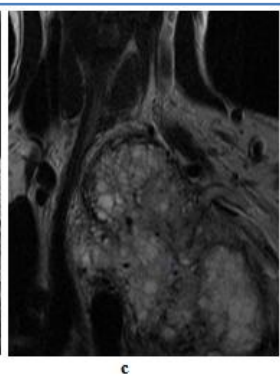

coronal T2
Multilocular lytic lesion process responsible for lysis of the body and the posterior arch of D1, hypo T1 signal hyper heterogeneous signal $\mathrm{T} 2$

This process is heterogeneously enhanced after injection of gadolinium, responsible for endocanal extension with spinal cord compression (Fig 7).

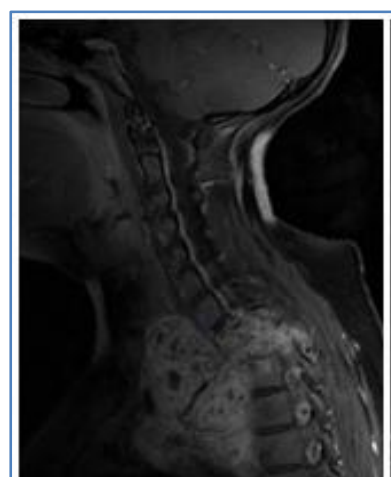

a

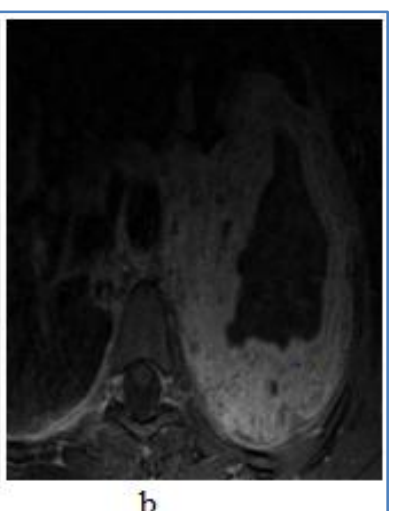

b
Fig-7: A- Sagittal T1 FAT-SAT after injection of gadolinium 


\section{B-Axial T1 FAT-SAT after injection of gadolinium}

This process is heterogeneously enhanced after injection of gadolinium, responsible for endocanal extension with spinal cord compression

The patient benefited from several CT-guided biopsies, the anatomopathological study demonstrated the presence of Giant cell tumor, colonized by an aneurysmal cyst.

\section{DISCUSSION}

Giant-cell tumours of bone were probably first described by Cooper and Travers in 1818. The name giant-cell tumour was introduced by Bloodgood (1919) [1]. The giant cell bone tumor rarely affects the spine (1 to $2 \%$ of cases)[2].

Very aggressive tumor, performing pure bone lysis, breaking the cortical bone, and extending to the paravertebral soft tissues, intraductal nerve structures [3]

Imaging plays a key role in the management of this pathology. Standard radiography: bone defect with or without clear limits (type IB or IC of the Lodwick classification) [4]. The CT scan perfectly analyzes the tumor matrix (tissue mass whose density varies from 20 to $60 \mathrm{HU})$ and the cortical lysis [5].

MRI appreciates better the extension to the soft tissues and nerve structures. Arteriography is performed as part of a preoperative embolization Interventional imaging allows to make the diagnosis of certainty through CT-guided bone biopsy [6].

The association of vertebral giant cell tumor and Aneurysmal Cyst,is found in almost $15 \%$ of cases [7]. Above all, it is MRI that reveals this association by showing a mutilocular cyst lesion within the tumor. This association is responsible for tumor hypervascularization, which may require one or more embolization sessions before excision [8].

\section{CONCLUSION}

The giant cell tumor with vertebral location is a very aggressive tumor. IT can be associated with an aneurysmal cyst responsible for tumor hyper vascularization, necessitating preoperative embolization. Nonspecific radiological aspect. MRI can better characterize this lesion. Need for multidisciplinary discussion.

\section{Abbreviations \\ CT: Computed tomography.}

MRI: Magnetic Resonance Imaging. HU: Hounsfield Unit

\section{ACKNOWLEDGEMENTS}

We thank the patient for giving his informed consent to publish this case report.

\section{REFERENCES}

1. Verviest H. Giant-cell tumours and aneurysmal bone cyst of the spine. The journal of bone and joint sugery. 1965; 14(4): 699.

2. Chagnon S, Vallée C, Chevrot A, Bléry M. Tumeur à cellules géantes. Traité de radiodiagnostic squelette normal. Neuroradiol App Locomoteur.1992;10(2):125.

3. Murphy MD, Nomikos GC, Flemming DJ, Gannon FH, Temple HT, Kransdorf MJ. From the archives of AFIP. Imaging of giant cell tumor and giant cell reparative granuloma of bone: Radiologic-pathologic correlation.Radiographics.2001;34(3-5) : 88 .

4. Lodwick GS, Wilson AJ, Farrell C, Virtana P, Smeltzer FM, Dittrich F. Estimating rate of growth in bone lesions. Observer performance and error Radiology. 2008;22(1-2) : 90.

5. Blum A, Lecocq S, Roch D, Louis M, Wassel J, Mosei A. Tumeurs épiphysaires: orientations diagnostiques. J Radiol. 2009; 12(4-6): 432.

6. El Haddad A, Bassou D, Chaouir S, Amil T, Hanine A. Localisation rare d'une tumeur à cellules géantes au niveau du rachis lombaire. Journal de radiologie. 2011;55(4-5) : 511 .

7. Van Dyck P, Vanhoenacker FM, Vogel J, Venstermans C, Kroon HM, Gielen J. Prevalence, extension and characteristics of fluid-fluid-levels in bone and soft tissue tumor. Eur Radiol.2006; 16: 2644-51.

8. Cebula H, Pham QT, Debry C, Froelich S. Tumeur à cellules génates de $\mathrm{C} 2$ colonissée par un kyste anévrysmal: A propos d'un cas. Neurochirurgie. $2009 ; 55(4-5)$ : 511. 